\section{Archivos de Cardiología de México}

\title{
Hallazgo incidental de arco aórtico derecho o en espejo
}

\section{Incidental finding of a right or mirror aortic arch}

\section{Nora García-Borges ${ }^{1 *}$, Saray Ayllón-Gámez² y Victoria García-Blanco 3}

${ }^{1}$ Servicio de Cirugía Cardiovascular, Hospital Regional de Málaga; ${ }^{2}$ Servicio de Cirugía General, Hospital de Ronda; ${ }^{3}$ Servicio de Angiología y Cirugía Vascular, Hospital Clínico de Málaga. Málaga, España

Se presenta el caso de una paciente de 50 años con antecedentes personales de hipertirodismo, en seguimiento por neoplasia renal tratada con nefrectomía, cuya angiotomografía computarizada de control

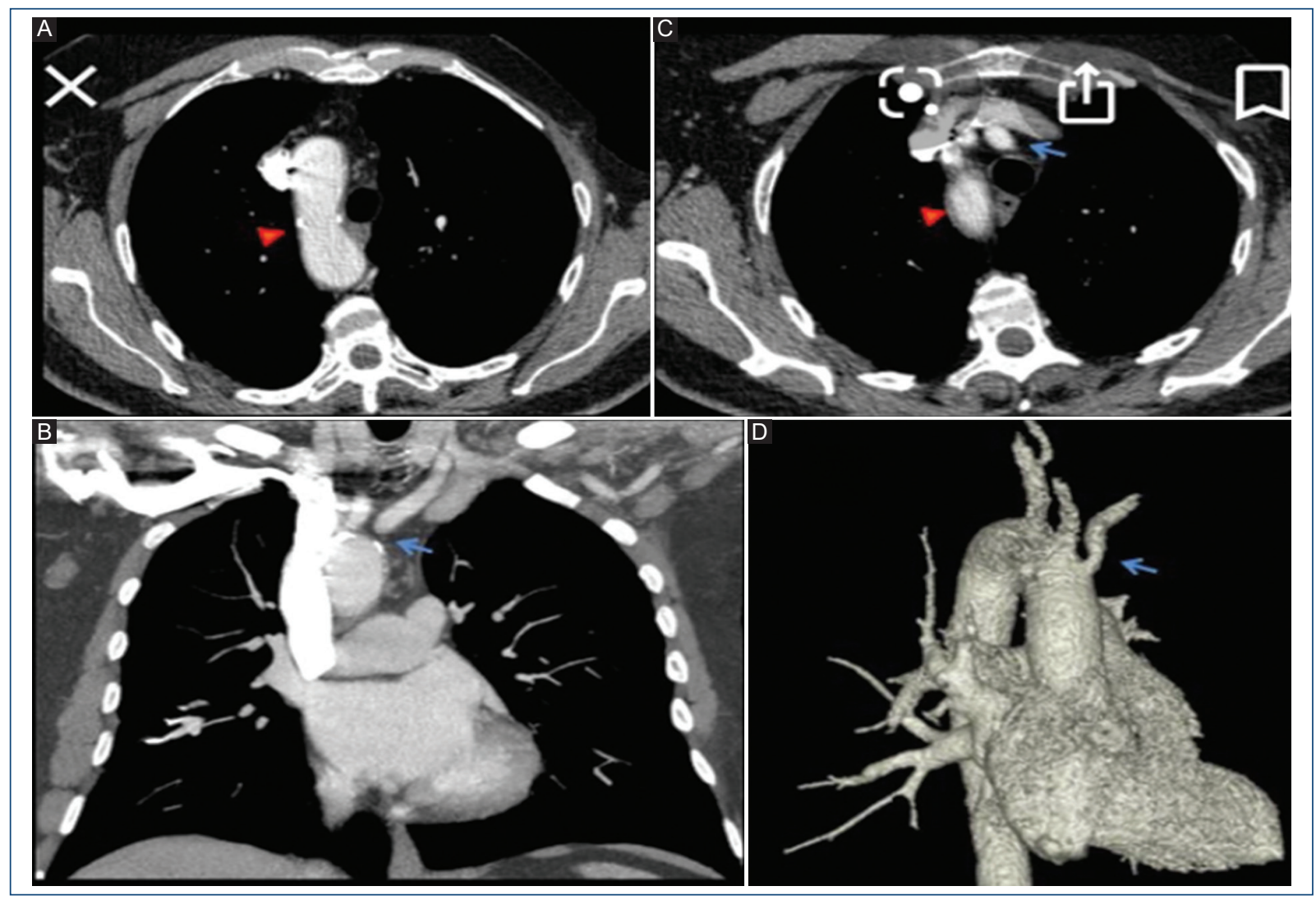

Figura 1. (A-D) Angiotomografía computarizada: arco aórtico derecho en espejo con salida normal de troncos supraaórticos.

\section{Correspondencia:}

*Nora García-Borges

E-mail: Noragb89@gmail.com
Fecha de recepción: 29-12-2020

Fecha de aceptación: 24-05-2021 DOI: $10.24875 /$ ACM.20000575
Disponible en internet: 03-01-2022 Arch Cardiol Mex. 2022;92(1):113-115 www.archivoscardiologia.com

1405-9940 / ๔ 2021 Instituto Nacional de Cardiología Ignacio Chávez. Publicado por Permanyer. Este es un artículo open access bajo la licencia CC BY-NC-ND (http://creativecommons.org/licenses/by-nc-nd/4.0/). 


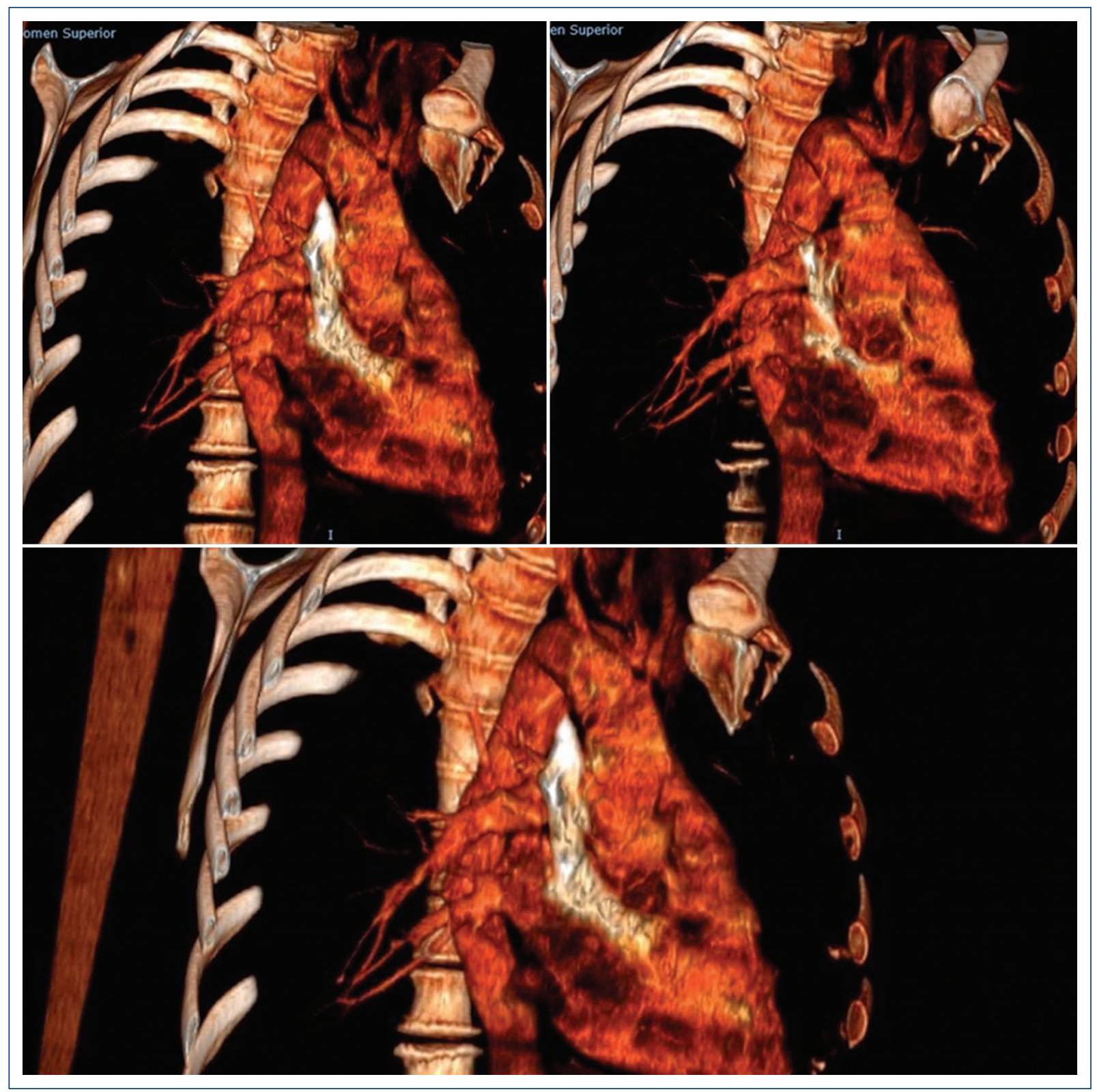

Figura 2. Reconstrucciones tridimensionales: arco aórtico derecho en espejo.

(Fig. 1 y 2) documentó de forma incidental un arco aórtico derecho aislado, sin ninguna clínica cardiovascular adjunta. Asimismo, no mostraba ningún hallazgo anormal en la exploración física ni en la auscultación cardíaca. Las alteraciones congénitas del arco aórtico son muy raras, con una incidencia cercana al $2 \%$ y el arco aórtico derecho representa el $10 \%$ de éstas. El arco aórtico derecho puede aparecer de las siguientes formas: aislado, como en el caso presentado; en relación con otras malformaciones cardíacas o extracardíacas; o en vinculación con cromosomopatías. Su diagnóstico se establece la mayoría de las veces en la etapa fetal, sobre todo el subtipo que forma anillos vasculares alrededor de la tráquea, mientras que otras formas pueden pasar inadvertidas. Éste es el caso de la paciente, denominado en particular arco aórtico derecho con imagen especular, ya que los troncos supraaórticos no presentan alteraciones, sino que se originan de la aorta y proyectan una imagen exacta en espejo con respecto al arco aórtico normal. Además, se completó un estudio con ecocardiografía que descartó malformaciones cardíacas. Por lo tanto, no se requirió ningún tratamiento para la alteración congénita y sólo se indicaron revisiones cardiológicas periódicas. ${ }^{1-3}$ 


\section{Financiamiento}

Esta investigación no ha recibido ninguna beca específica de agencias de los sectores público, comercial o sin ánimo de lucro.

\section{Conflicto de intereses}

Ninguno.

\section{Responsabilidades éticas}

Protección de personas y animales. Los autores declaran que para esta investigación no se han realizado experimentos en seres humanos ni en animales.
Confidencialidad de los datos. Los autores declaran que han seguido los protocolos de su centro de trabajo sobre la publicación de datos de pacientes.

Derecho a la privacidad y consentimiento informado. Los autores han obtenido el consentimiento informado de los pacientes o sujetos referidos en el artículo. Este documento obra en poder del autor de correspondencia.

\section{Bibliografía}

1. Moreno R, Bravo C. Visualización ecográfica y diagnóstico prenatal del arco aórtico derecho. Diagnóstico prenatal. 2013;24(1):32-35.

2. Delgado C, Mestre J, Barturen F. Arco aórtico derecho y arteria subclavia izquierda aberrante. Rev Esp Cardiol. 2003;56:817.

3. Martínez E, Marrero JM. Disfagia y arco aórtico derecho. Gastroenterología y Hepatología. 2007;30(6):373. 